\title{
Osmotically assisted reverse osmosis (OARO): Five approaches to dewatering saline brines using pressure-driven membrane processes
}

\author{
Christian D. Peters ${ }^{1}$ and Nicholas P. Hankins ${ }^{1}$ \\ ${ }^{1}$ Department of Engineering Science, The University of Oxford, Parks Road, OX3 1PJ, \\ Oxford, UK
}

August 2018

\begin{abstract}
The ability of osmotically assisted reverse osmosis to draw water from concentrated brine $(>75 \mathrm{~g} / L)$ can be attributed to the combined effect of reducing the trans-

5 membrane osmotic pressure difference via a draw solution, and operating at high hydraulic feed pressures. This approach has been incorporated into a standard ultrafiltration and reverse osmosis desalination plant to increase the process recovery. In total, five different OARO integrated flow processes are modelled numerically to determine their technical and economical feasibility in maximising the process recovery. Three of the five presented OARO integrated flow processes are novel, and offer technical and economical advantages over the previously proposed OARO processes.

At lower feed salinities, OA-5, which is a new process, is the optimal OARO integrated flow process. Recoveries of up to $72 \%$ from a $35 \mathrm{~g} / \mathrm{L}$ saline feed are possible when operating at the membrane burst pres20 sure of 48.3 bar. Furthermore, the energy consumption of OA-5 is approximately $4.00 \mathrm{kWh} / \mathrm{m}^{3}$, which is significantly lower than that in currently employed high recovery thermal processes, such as mechanical vapour compression.

$25 \quad$ OA-3 is another original OARO integrated flow process and is the most attractive at a higher feed salinity of $70 \mathrm{~g} / \mathrm{L}$. The maximum recovery of $44 \%$ is achieved at an average energy consumption of $6.37 \mathrm{kWh} / \mathrm{m}^{3}$. The results presented in this article demonstrate that so pressure-based membrane processes can competitively concentrate brine streams to concentrations of up to $125 \mathrm{~g} / \mathrm{L}$.
\end{abstract}

Keywords: OARO; Osmotically assisted reverse 35 osmosis; OED; Osmotically enhanced dewatering; High recovery membrane process; MSRO; Multi-stage reverse osmosis

\section{Introduction}

Of the currently available desalination technologies, reverse osmosis ( $\mathrm{RO})$ is the most energy efficient choice, but is confined by practical issues to a maximum feedwater salinity of approximately $75 \mathrm{~g} / \mathrm{L}$ (Tsai et al. 2017). Being a pressure driven process, irreversible losses associated with a phase transition of the prod- thermal desalination processes, can be avoided (Tong \& Elimelech 2016). This allows RO to operate closer to the thermodynamic minimum energy of separation. As described in Elimelech \& Phillip (2011), the minimum energy of separation increases with process recovery and the resulting increase in the osmotic pressure of the feed solution. However, the maximum operating pressure, required to overcome the feed osmotic pressure, is limited by the membrane burst pressure (Bartholomew et al. 2017). This limits the maximum recovery of RO, especially at the higher feed concentrations $(>75 \mathrm{~g} / \mathrm{L})$.

Unfortunately, lower process recoveries have adverse economic and environmental implications. Larger volumes of feedwater must be extracted and pre-treated for the production of the same amount of freshwater. Furthermore, larger volumes of brine must be disposed of. According to Morillo et al. (2014), brine disposal costs constitute between $5 \%$ and $33 \%$ of the total cost of desalination. A reduction in brine volume can lower the incurred costs associated with its disposal and treatment, which may be required to meet local regulations and to reduce its environmental impact. Thus, more environmentally friendly brine management solutions may become economically feasible with lower brine volumes and higher process recoveries.

Dewatering such highly saline brines $(>75 \mathrm{~g} / \mathrm{L}$ ) poses considerable technical challenges. Thermal processes, such as mechanical vapour compression (MVC), are currently still the prevailing techniques applied to achieve this (Chen \& Yip 2018). In Davenport et al. (2018), a two-stage MVC process is modelled to concentrate a $70 \mathrm{~g} / \mathrm{L}$ saline stream to $250 \mathrm{~g} / \mathrm{L}$. MVC is chosen due to its effective heat recovery, but it still consumes $24 \mathrm{kWh} / \mathrm{m}^{3}$. In comparison, the minimum energy required by a thermodynamically reversible process per unit volume of product water is approximately $3.5 \mathrm{kWh} / \mathrm{m}^{3}$ (Davenport et al. 2018).

The ability to withdraw water from saline brines $(50-350 \mathrm{~g} / \mathrm{L}$ TDS $)$ in a more energy efficient manner would be beneficial for many industries, such as the oil, gas and energy sectors (Bartholomew et al. 2017). For example, it would facilitate the reuse of high salinity wastewaters, and allow other processes, such as inland desalination, to circumvent regulatory, economical and environmental restrictions due to brine volume minimisation (Davenport et al. 2018). Furthermore, zeroliquid discharge processes could increase profit mar- 
gins, as valuable by-products, such as minerals, are

Recently, a potentially more energy-efficient solution for dewatering saline brines was proposed by Bartholomew et al. (2017) and Chen \& Yip (2018). This process is termed osmotically assisted reverse osmosis (OARO) and is also a pressure-driven membrane process.

In this article, the technical and economic viability of five OARO integrated flow processes, of which three are novel, is determined by modelling the processes using the solution-diffusion model. The objective of these processes is to recover $72 \%$ and $44 \%$ of the freshwater from feed solutions with a respective salinity of $35 \mathrm{~g} / \mathrm{L}$ and $70 \mathrm{~g} / \mathrm{L}$. Both scenarios result in the same final brine concentration of $125 \mathrm{~g} / \mathrm{L}$. This brine concentration target is $50 \mathrm{~g} / \mathrm{L}$ above the generally achievable RO brine concentration and would result in a $40 \%$ reduction in brine volume. A similar brine concentration target has been set in Chen \& Yip (2018).

The optimal OARO integrated flow process is cho-

Energy consumption: As suggested in Semiat (2000), energy consumption is the main contributor, with a share of $44 \%$ of the overall operational expenditures of a typical seawater reverse osmosis (SWRO) desalination plant. The energy consumption is therefore assumed to be representative of the overall process operational costs. In section 6, the energy consumption of the entire desalination process is modelled. This includes the energy consumed by the seawater intake, pre-treatment, brine discharge and post-treatment.

Capital cost: Henthorne \& Boysen (2015) and Moser et al. (2015) both state that the intake, pretreatment and brine discharge contribute somewhere between $23 \%$ and $33 \%$ to the total capital expenditures of a SWRO plant. These costs can be excluded from the comparison, as all the OARO integrated flow processes operate with the same feed and recovery and thus have similar intake, pre-treatment and brine discharge costs. However, the cost contribution of the desalination system itself, which is mainly comprised of the cost incurred by the pressure vessels, is approximately $35 \%$ of the total capital expenditures of a SWRO plant. As the required number of pressure vessels varies for each process, the capital cost of each OARO integrated flow process will be linked to this number. The required number of pressure vessels is determined for a permeate production of $1000 \mathrm{~m}^{3} / \mathrm{h}$ at the desired recoveries. Capital costs associated with the high pressure pumps (HPP) and the energy recovery devices (ERD) are also included.

Permeate salinity: The maximum allowable permeate salinity is $500 \mathrm{mg} / \mathrm{L}$ TDS, as stated in the World Health Organisation (WHO) standards for drinking water (Pohl et al. 2009).
Operating pressure: The maximum operating pressure $P_{O A}$ is restricted by practical pressure limits of the OARO membrane and module. As explained in section 2, the burst pressure is assumed to be 48.3 bar. The burst pressure is defined as the maximum allowable transmembrane pressure (TMP) under which the selectivity of the membrane's active layer is not compromised.

\section{Osmotically assisted reverse osmosis (OARO)}

Osmotically assisted reverse osmosis incorporates both the forward osmosis (FO) and reverse osmosis working principles. However, compared to FO, the draw solution is less concentrated than the feed solution and is only utilised to lower the osmotic pressure difference across the membrane (Kim, Kim \& Hong 2018). Thus, OARO can be operated at lower applied hydraulic pressures than conventional RO, which permits dewatering of more saline feed streams without exceeding the maximum allowable hydraulic pressure of the membrane module. Additionally, the lower operating pressures make OARO more energy efficient than conventional $\mathrm{RO}$, but a secondary purification process is required to lower the salinity of the diluted draw solution to freshwater standards. The OARO process is depicted in figure 1.

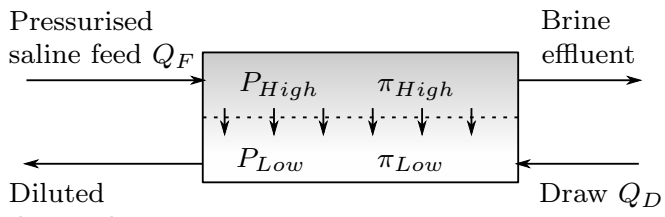

draw solution

Figure 1: Osmotically assisted reverse osmosis

Ideally, the OARO membrane is selective (low solute permeability coefficient $B$ ) and is water permeable (high water permeability coefficient $A$ ). Furthermore, the ideal OARO membrane has a low structural parameter $S$, which is related to the structural properties of the membrane's support layer. These membrane requirements are similar to those required for pressure retarded osmosis (PRO). However, there are currently few, if any, commercially available PRO membranes, and therefore FO membranes are generally employed instead (Hickenbottom et al. 2016).

Internal concentration polarisation (ICP), which hinders the osmotic pressure of the draw solution, is less important if $S$ is minimised. To reduce $S$, the membrane support layer must be thin, non-tortuous and highly porous, which unfortunately also results in the reduction of the membrane's structural strength and integrity. This is especially problematic at high hydraulic pressures, which can lead to severe membrane deformation and eventually to the rupture of the membrane's active layer. For example, conventional RO membranes have a thick and dense support layer 
( $S=37.5 \mathrm{~mm}$ for SWRO and $S=14 \mathrm{~mm}$ for brackish water RO (BWRO)) as they have to withstand high feed pressures, which can reach up to 85 bar and 40 bar for SWRO and BWRO respectively (Alsvik \& Hägg 2013). On the other hand, FO membranes have a thin support layer $(S<0.7 \mathrm{~mm})$ to reduce ICP and no high hydraulic pressures are applied (Alsvik \& Hägg 2013).

In Straub et al. (2014), a maximum burst pressure of 48.3 bar was achieved in PRO operation for a commercially available thin-film composite (TFC) FO membrane backed by two layers of dense tricot woven fabric. Even higher burst pressures, of up to 70 bar, were achieved by Madsen et al. (2017) for three cellulose acetate (CTA) FO membranes. However, a porous steel plate was used as feed spacer in the experimental PRO set-up. Implementing porous steel plates as spacers in spiral wound membrane modules is not practical or economically feasible. On the other hand, the tricot woven fabric is commonly utilised in commercial SWRO membrane modules. Therefore, the maximum practical burst pressure is assumed to be 48.3 bar and not 70 bar.

\subsection{Governing equations for OARO and RO}

Generally, two OARO membrane orientations are possible, due to the asymmetrical nature of the TFC membrane. In AL-FS mode, the active layer faces the feed solution and the draw solution comes into direct contact with the porous support layer. On the other hand, in AL-DS mode the active layer faces the draw solution and the feed solution enters the porous support layer. If the feed solution is pressurised, then the membrane is forced against the draw solution spacer. In AL-DS mode, the active layer comes into direct contact with spacer and the active area of the membrane is lowered. In this fashion, a water flux reduction was observed in Oh et al. (2014). It was also found that membrane damage occurred if the hydraulic feed pressure exceeded 20.7 bar for a TFC FO membrane. In AL-FS me porous support layer is pressed against the draw solution spacer and no reduction in active membrane area was observed. Additionally, no membrane damage was observed for hydraulic pressures of up to 27.6 bar. Therefore, all OARO processes are generally tion is vital to prevent membrane damage by the draw solution spacer, especially if spiral wound modules are used in the OARO process.

The AL-FS membrane orientation and its respecconcentration profile are illustrated in figure 2 . As shown, the osmotic pressure of the feed solution $\pi_{F}$ increases in the boundary layer due to concentrative external concentration polarisation (ECP). Solutes are rejected by the membrane's active layer and accumulate in its vicinity (Johnson et al. 2018). On the other hand, the draw solution's osmotic pressure $\pi_{D}$ decreases in the porous support layer and in the boundary layer, due to dilutive ICP and ECP respectively. Dilution of the draw solution in the support

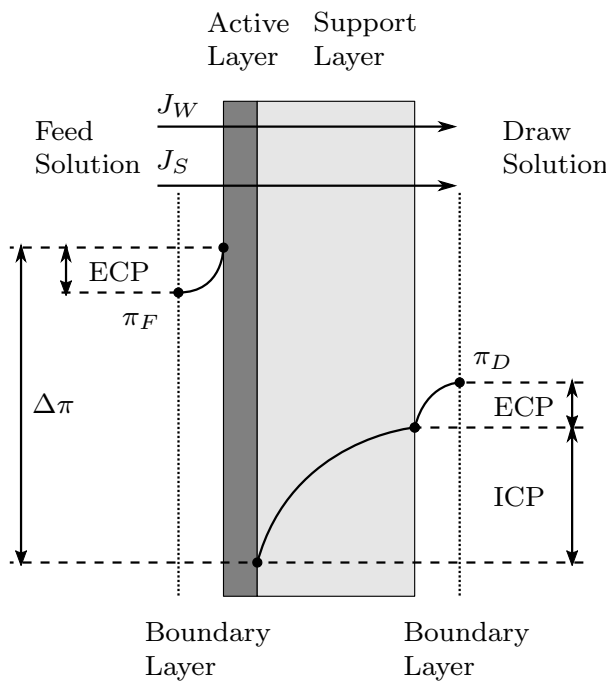

Figure 2: Concentration profile in the OARO process with ICP and ECP. Figure is adapted from $\mathrm{Oh}$ et al. (2014).

layer is counteracted by the back-diffusion of draw solute ions towards the active layer. Membranes with a lower structural parameter $S$ experience less resistance towards ion diffusion and thus ICP is less dominant (Shaffer et al. 2015). Both dilutive and concentrative ECP are more easily mitigated by altering hydrodynamic conditions, such as increasing turbulence (Wang 2016).

If the same solute is present in the feed and draw streams, then the lower concentration of the draw solution causes feed solutes to diffuse into the draw solution. This is not the case in forward osmosis, where the draw concentration exceeds that of the feed and reverse solute flux occurs. For FO, the solute flux $J_{S}$ would be in the opposite direction to that indicated in figure 2 . More importantly, ICP is more severe at higher draw concentrations. Thus, OARO is less affected by ICP than FO since the draw solution is less concentrated (Kim, Kim, Kim \& Hong 2018).

An advanced solution-diffusion model is utilised to model the OARO and RO processes. This model was previously used by Kim, Gwak \& Hong (2017) to model pressure assisted FO (PAFO). The depicted water flux $J_{W}$ and reverse solute flux $J_{S}$ can be expressed as:

$$
J_{W}=A\left(\frac{\pi_{D} \exp \left(-J_{W} K\right)-\pi_{F} \exp \left(\frac{J_{W}}{k_{F}}\right)}{1-\frac{B}{J_{W}}\left(\exp \left(-J_{W} K\right)-\exp \left(\frac{J_{W}}{k_{F}}\right)\right)}+\Delta P\right)
$$

and (Kim, Kim, Kim \& Hong 2018):

$$
J_{S}=B\left(\frac{C_{F} \exp \left(\frac{J_{W}}{k_{F}}\right)-C_{D} \exp \left(-J_{W} K\right)}{1-\frac{B}{J_{W}}\left(\exp \left(-J_{W} K\right)-\exp \left(\frac{J_{W}}{k_{F}}\right)\right)}\right)
$$

Both equations account for the effects of forward and reverse solute transport and concentration polarisation (Blandin et al. 2017). $K$ is given by:

$$
K=\left(1 / k_{F}+1 / k_{M}+1 / k_{D}\right)
$$

where $1 / k_{F}$ and $1 / k_{D}$ represent the external resistance to mass transfer in the feed and draw solution streams 
(Xiao et al. 2012). For membranes with a thick and less porous support layer, the solute resistance to diffusion in the support layer $1 / k_{M}$ is dominant, and is given by (Duan et al. 2014):

$$
\frac{1}{k_{M}}=\frac{S}{D}
$$
lution accuracy as the implicit scheme but converges more rapidly.

\section{Analysis of the stand-alone OARO process}

Before the OARO integrated flow processes are analysed in section 5 , it is important to understand the effect of varying the operating parameters of the standalone OARO process, which is depicted in figure 1. grated with the RO unit. All comparisons of the standalone OARO process are performed at a constant seawater (draw) and brine (pressurised saline feed) inlet salinity of $35 \mathrm{~g} / \mathrm{L}$ and $70 \mathrm{~g} / \mathrm{L}$, respectively. Further assumptions are that $\mathrm{NaCl}$ is the only solute and that the density $\left(1025 \mathrm{~kg} / \mathrm{m}^{3}\right)$ and temperature $\left(25^{\circ} \mathrm{C}\right)$ of the feed and draw streams are constant. For energy calculations, the mechanical efficiency of the pump and the energy recovery device are assumed to be $80 \%$ and $96 \%$, respectively (Voutchkov 2018). The number of membrane modules in series $n_{O A}$ is kept constant at 7 ; and each module has an active membrane area of $37 \mathrm{~m}^{2}$, which corresponds to the membrane area of conventional 8 inch Filmtec spiral wound modules (DOW Water Solutions 2017b).

Generally, the feed inlet flowrate $Q_{F}$ is set as $8 \mathrm{~m}^{3} / \mathrm{h}$ and the flowrate ratio $R R$, defined as the ratio between the draw and feed flowrates, is set as 1. Finally, the pressure loss in the feed and draw channels is modelled by:

$$
P_{L}=68.95 n_{O A}\left(15.85 Q_{F}\right)^{1.7}
$$

where the pressure loss $P_{L}$ is given in bar and $Q_{F}$ in $\mathrm{m}^{3} / \mathrm{s}$. This equation is adapted from DOW Water Solutions $(2017 b)$ for spiral wound modules.

\subsection{Optimal OARO membrane proper- ties}

SWRO desalination plants are generally designed to operate at an average water flux of approximately $10-15 L M H$ (Davenport et al. 2018). Optimally, the OARO process is operated at similar water fluxes to reduce capital expenditure, but this could be problematic as concentration polarisation is more severe at higher water fluxes. Assuming that ECP is negligible compared to ICP (by ensuring high cross-flow velocities), the draw solution's concentration polarisation factor $C P_{D}$ can be expressed as:

$$
C P_{D} \approx \exp \left(-J_{W} K\right) \approx \exp \left(-J_{W} S / D\right)
$$

This term is plotted in figure 3 for three different $S$ values with respect to the water flux. If $C P_{D}$ reaches zero, the draw solution concentration is effectively nullified and does not affect $J_{W}$ and $J_{S}$. Therefore, $S$ must be less than $1.5 \mathrm{~mm}$ for the draw solution to be effective at similar water fluxes to SWRO. In the following simulations, $S$ is kept constant at $0.57 \mathrm{~mm}$, which corresponds to the structural parameter of the TFC FO membrane used in Straub et al. (2014).

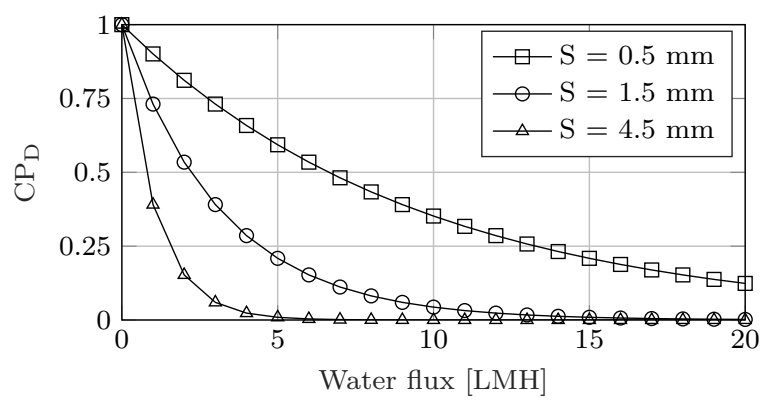

Figure 3: The concentration polarisation factor of the draw solution with respect to the water flux for three different structural parameters

As mentioned in Werber et al. (2016), dense polymeric membranes demonstrate a permeabilityselectivity trade-off. For TFC membranes, the following relationship is presumed: $B \propto A^{3}$, which means that an increase in a membrane's water permeability also leads to a significant increase in solute permeability (Yip \& Elimelech 2011). This is not ideal for the OARO process, as the membrane optimally possesses a high $A$ and a low $B$ value. Figure 4 displays the specific energy consumption (SEC) and diluted seawater salinity with respect to the OARO process recovery for three different types of membranes. The presented OARO recoveries are achieved by varying $P_{O A}$ between $40-80$ bar.

In addition to the TFC-FO membrane, which was used by Straub et al. (2014), a nanofiltration (NF90) and reverse osmosis (SW30HRLE) membrane are also modelled. The NF90 nanofiltration membrane is chosen for this comparison, as it shows high rejection ratios for both monovalent and bivalent ions when compared to other nanofiltration membranes, such as the NF270 
or NF200 membrane (Zhou et al. 2015). According to the manufacturer, the SW30HRLE seawater reverse osmosis membrane element combines high rejection and low energy requirements and is therefore chosen for this comparison (DOW Water Solutions 2017a). Each membrane's properties are given in table 1 .

For this simulation, it is assumed that it is possible to manufacture all three membranes with the same thin and porous support layer $(S=0.57 \mathrm{~mm})$. The nanofiltration (NF90) and the SWRO (SW30HRLE) membrane properties were validated using ROSA, which is an RO system analysis (ROSA) software developed by the membrane manufacturer DOW Filmtec (Altaee 2012).

Table 1: Membrane properties of the three simulated membranes

\begin{tabular}{cccc}
\hline Name & Manufacturer & $\begin{array}{c}A \\
{[L M H / \text { bar }]}\end{array}$ & $\begin{array}{c}B \\
{[L M H]}\end{array}$ \\
\hline NF90 & DOW Filmtec & 6.25 & 1.68 \\
TFC-FO & HTI & 2.49 & 0.39 \\
SW30HRLE & DOW Filmtec & 1.13 & 0.08 \\
\hline
\end{tabular}

The shaded areas in figure 4 represent infeasible operating conditions, as the feed pressure $P_{O A}$ exceeds the burst pressure of 48.3 bar. At equivalent feed pressures, the more permeable membranes achieve a higher process recovery, as the water flux $J_{W}$ increases proportionally with $A$. Almost $23 \%$ of the brine stream can be recovered when utilising the NF90 membrane at the burst pressure. On the other hand, the recovery only reaches $15.2 \%$ and $12.3 \%$ when using the TFCFO and the SW30HRLE reverse osmosis membrane, spectively.

Figure 4 displays the diluted seawater salinity for all three membranes. In general, a higher dilution of the OARO draw solution is preferred, as a secondary purification process is utilised to further desalinate this stream. As shown in the figure, a similar diluted seawater salinity is observed when utilising either membrane and operating at the membrane burst pressure. This is true even though the membrane properties $A$ and $B$ vary significantly between the chosen membranes. As previously mentioned, dense polymeric membranes with a higher permeability have a lower selectivity due to the permeability-selectivity trade-off phenomenon. Thus, choosing a more permeable membrane, such as the NF90 membrane, leads to a simultaneous increase similarity in draw dilution for all three membranes under the defined OARO operating conditions.

The specific energy consumption of the OARO process, operated at the membrane burst pressure, reduces (TFC-FO) to $2.40 \mathrm{kWh} / \mathrm{m}^{3}$ when using the NF90 membrane instead of the more selective membranes. To conclude, OARO processes seem to benefit more from water permeability than from selectivity in the membrane, as a similar dilution of the draw stream is achieved at a lower specific energy consumption. Thus, tight nanofiltration membranes with a thin and porous sup- port layer should be further developed for these type of applications. However, these membranes are not commercially available with such thin support layers. Since the TFC-FO membrane is commercially available, it is chosen for the subsequent simulations.
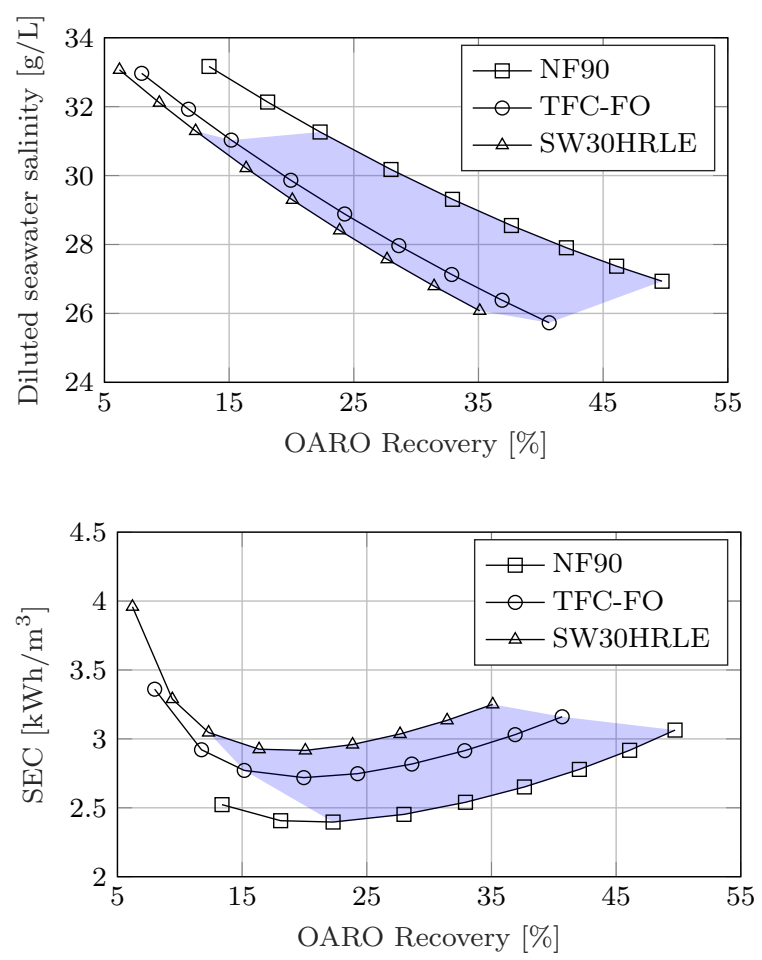

Figure 4: Diluted seawater salinity and specific energy consumption for three different membranes with respect to OARO process recovery. $\left(Q_{F}=8 \mathrm{~m}^{3} / \mathrm{h}\right.$ and $R R=1)$

\subsection{Optimal OARO feed flowrate}

The process recovery $Y_{S}$ is inversely dependent to the feed flowrate $Q_{F}$ :

$$
Y_{S}=\frac{Q_{P}}{Q_{F}}
$$

where $Q_{P}$ is the flowrate of the permeate that moves from the feed to the draw solution. $Q_{P}$ is also dependent on $Q_{F}$, as $J_{W}$ and $J_{S}$ are indirectly affected by changes in the feed flowrate. The pressure drop $P_{L}$ in the OARO feed channel increases with $Q_{F}$, as shown by equation (5). An increase in $P_{L}$ over the length of the membrane module reduces the transmembrane pressure difference, which results in a reduction in $Q_{P}$. On the other hand, at higher flowrates, external concentration polarisation is less pronounced, as enhanced mass transfer occurs due to higher turbulence in the feed channels.

The net effect of $Q_{F}$ on the OARO process recovery is depicted in figure 5. As shown, the process recovery increases from $10.6 \%$ to $23.0 \%$ if operating at the membrane burst pressure and the flowrate is reduced from $12 \mathrm{~m}^{3} / \mathrm{h}$ to $4 \mathrm{~m}^{3} / \mathrm{h}$. This suggests that the reduction in $P_{L}$ and the smaller denominator in equation (7) 
affect the process recovery more than the increase in

ECP due to the lower flowrates.

The higher OARO process recovery at lower $Q_{F}$ and equivalent feed pressures result in a lower diluted seawater salinity, as shown in figure 5. Furthermore, the specific energy consumption reduces with a reduction in $Q_{F}$ when operating at the bursting pressure. This can be attributed to the higher recovery and lower pressure drop in the OARO feed channels.
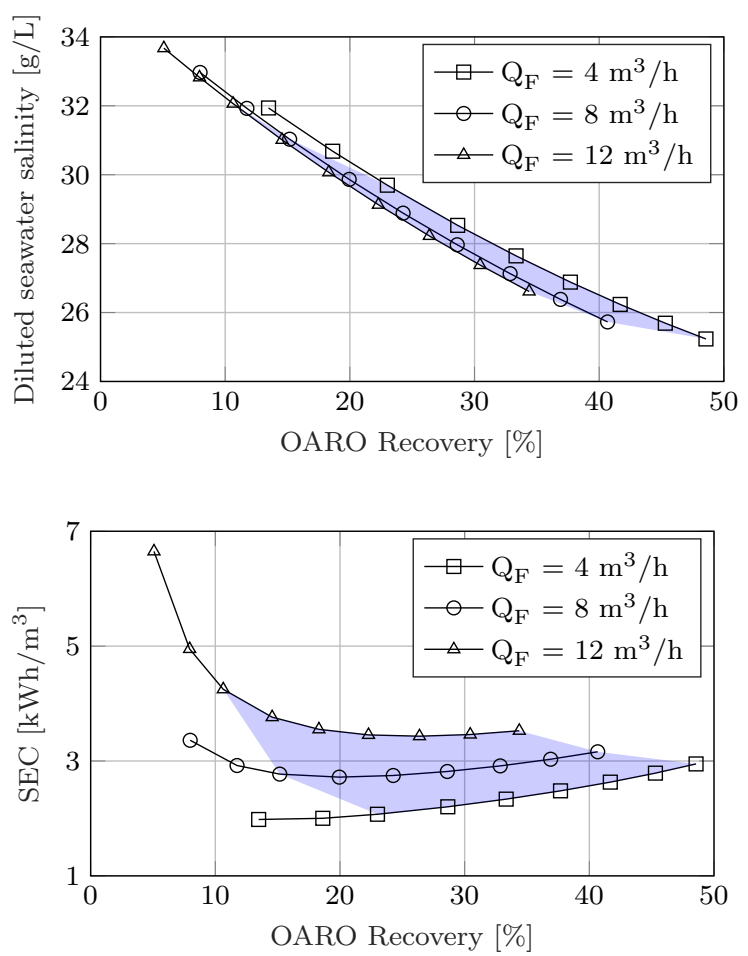

Figure 5: Specific energy consumption for three different feed flowrates with respect to OARO process recovery. (TFC-FO membrane with $R R=1$ )

The higher system recovery, better dilution of the draw stream and the lower energy consumption suggest Nevertheless, lower feed flowrates result in higher capital expenditures, because more OARO pressure vessels are required in parallel to process the same overall feed rate. Another problem arising from low feed flowrates tions (2017b), a general guideline is given for the concentrate flowrate, which should not be less than $3 \mathrm{~m}^{3} / \mathrm{h}$ if the feed silt density index (SDI) is approximately 3 . Lower SDI values represent a better feedwater quality, and can be achieved by more rigorous pre-treatment.

The trade-off between recovery, energy consumption, capital cost and fouling suggests that an intermediate flowrate is the best choice for the OARO process. $Q_{F}$ is chosen to be $6 \mathrm{~m}^{3} / \mathrm{h}$ for the simulations in section 6 , where it is important to show that the OARO process can be operated below its burst pressure while achieving the set recoveries.

\subsection{Optimal flowrate ratio between OARO streams}

The flowrate ratio $R R$ is defined as:

$$
R R=\frac{Q_{D}}{Q_{F}}
$$

where $Q_{D}$ is the inlet flowrate of the draw solution and $Q_{F}$ is the inlet flowrate of the feed solution (see figure 1). Figure 6 displays the diluted seawater salinity and the specific energy consumption for three different $R R$ values. At lower $R R$ values, only a fraction of the seawater feed is used in the OARO process as draw solution whereas the other fraction bypasses the OARO module. The salinity displayed in figure 6 is the final diluted seawater salinity when both streams are mixed again.

The figures indicate that the $R R$ value has a negligible effect on the OARO recovery when operated at the same $P_{O A}$. Furthermore, the diluted seawater salinity is reduced as $R R$ increases. Larger $R R$ values indicate a more voluminous draw stream, which is thus more difficult to dilute. The salt diffusion from the brine to the seawater stream is reduced, as the transmembrane concentration difference is lower throughout the OARO module when $R R$ is larger.

If $R R$ is greater than 1 , the pressure loss in the draw stream is more severe for no additional increase in recovery. Furthermore, figure 6 shows that the specific energy consumption is significantly higher at the burst pressure if $R R=1.5$. In practice, $R R$ will be less than 1 , as the spacer in the OARO draw channel must be more dense than the feed spacer to prevent membrane deformation under high feed pressures. For example, in Jeon et al. (2018) the maximum tested $R R$ value never exceeded 0.6 for an FO spiral wound module. To conserve energy and for practical reasons, $R R$ is chosen here onwards to be 1 as the draw stream dilution is also slightly better than for $R R=0.5$. The better dilution of the OARO draw stream is beneficial, as it is more easily desalinated in a secondary purification process.

\subsection{OARO feed pressure}

Assuming that membranes and modules can be designed to achieve higher burst pressures, the shaded areas in figure 4 , figure 5 and figure 6 become feasible operating regions. Each plot marker represents an increase in pressure by 5 bar up to a maximum pressure of 80 bar. As shown in these figures, the specific energy consumption remains relatively constant when increasing $P_{O A}$ above the current burst pressure. This can be attributed to the simultaneous increase in energy consumption and recovery at higher $P_{O A}$.

From equation (1) and equation (2) it can be seen that the transmembrane pressure difference directly affects the water flux $J_{W}$, but not the solute flux $J_{S}$. The water flux changes proportionally with the feed pressure, which in turn changes the concentration polarisation factors that affect both $J_{W}$ and $J_{S}$. Therefore, 

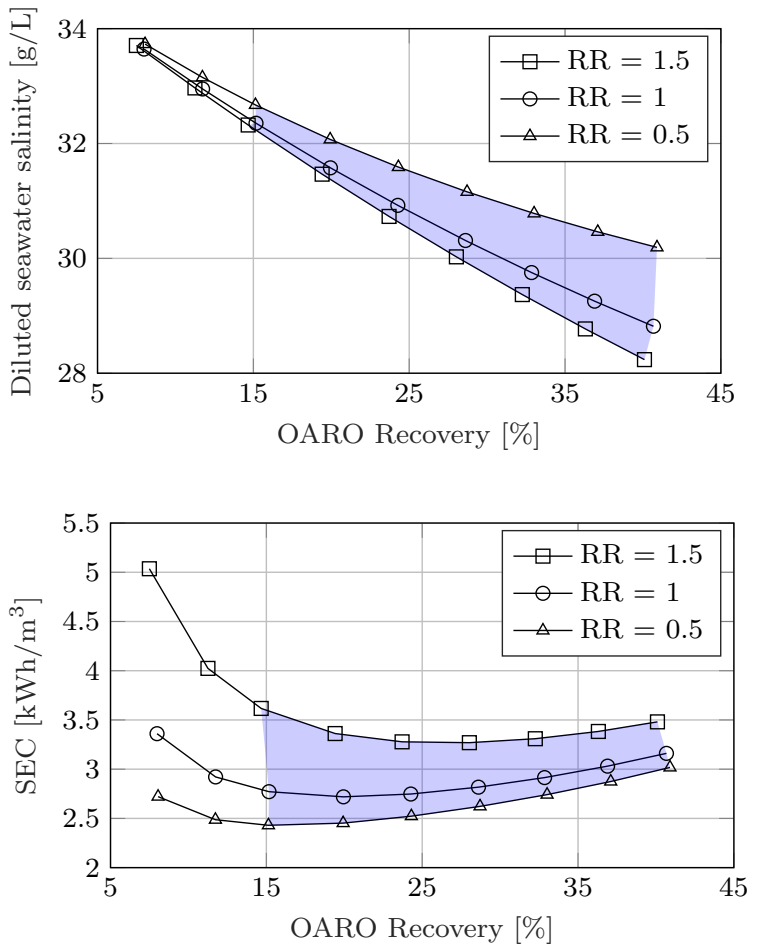

Figure 6: Diluted seawater salinity and specific energy consumption for three flowrate ratios $R R$ with respect to OARO process recovery. (TFC-FO membrane with $\left.Q_{F}=8 m^{3} / h\right)$

an increase in $P_{O A}$ results in a higher process recovery due to the higher water flux. On the other hand, the change in solute flux is less severe when altering $P_{O A}$. An increase in feed pressure thus leads to an improvement of the OARO draw stream dilution.

Madsen et al. (2017) show that current FO membranes are capable of withstanding high feed pressures of up to 70 bar if they are sufficiently supported by the membrane module and spacer. Thus, the development of highly permeable but rigid permeate spacers and of membrane modules with high packing densities is essential to improve the OARO process.

\section{The standard UF-RO process}

In the following section, the OARO process is incorporated into the standard UF-RO process, depicted in figure 7 , to achieve the specified recoveries. Although a single UF and RO process are depicted, each process consists of a number of membrane modules in parallel $\left(N_{U F}\right.$ and $\left.N_{R O}\right)$ to process the overall feed rate. The operating conditions of this UF-RO process will remain constant for all simulations. A single stage RO process is chosen, where each pressure vessel contains 78 -inch spiral wound membrane modules (Voutchkov 2018). The RO operating pressure and feed flowrate are set at 80 bar and $12 \mathrm{~m}^{3} / \mathrm{h}$, respectively. These process parameters are representative of a general $\mathrm{RO}$ process for large operations (DOW Water Solutions 2017b).
Table 2 presents the recoveries achieved by the UFRO process for the two specified feed concentrations. Relatively high recoveries are achieved for the UFRO process when operating at 80 bar, which is the typical maximum operating pressure of RO (Davenport et al. 2018). DOW Water Solutions (2017b) suggests that an additional flow factor $F F$ is incorporated into equation (1) to adjust the modelled water flux for reversible/irreversible fouling and scaling. Generally, $F F$ is 0.7 if the seawater feed is treated by ultrafiltration (UF) and SDI is below 3. However, empirical data regarding water flux reduction due to reversible/irreversible fouling or scaling is not available; thus, $F F=1$ here. In other words, a pure $\mathrm{NaCl}$ feed is considered in the simulations. With a real seawater feed, fouling and scaling phenomena cannot be neglected and the achievable recoveries will reduce with operational time. The extent is however unknown.

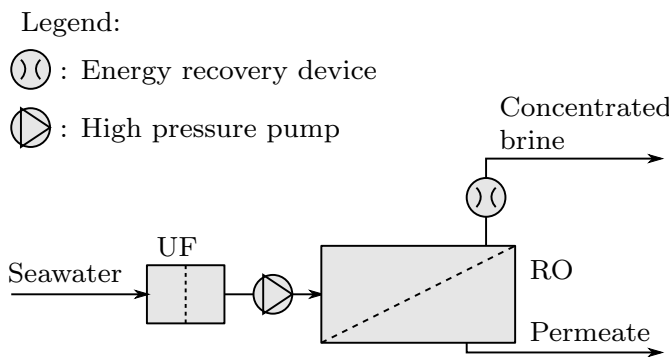

Figure 7: The UF-RO reference model

Table 2 also presents the modelled energy consumption of the UF-RO process. Fane (2018) mentions that the overall energy consumption of modern SWRO desalination plants lies in the range of $3.0 \mathrm{kWh} / \mathrm{m}^{3}$ to $3.5 \mathrm{kWh} / \mathrm{m}^{3}$. The energy consumption of the UF-RO process lies slightly above this range for a seawater salinity $C_{I N}$ of $35 \mathrm{~g} / \mathrm{L}$. The efficiency of the high pressure pump and energy recovery device are equivalent to those for the OARO process presented in section 3. The energy breakdown for a typical SWRO desalination plant, given in Voutchkov (2018), is assumed to be at a $50 \%$ system recovery, and is used to determine the additional energy expenditures associated with the intake, pre-treatment, brine discharge and post-treatment. At the same recovery, the UF$\mathrm{RO}$ plant presented in figure 7 consumes $0.19 \mathrm{kWh} / \mathrm{m}^{3}$, $0.12 \mathrm{kWh} / \mathrm{m}^{3}$ and $0.18 \mathrm{kWh} / \mathrm{m}^{3}$ for the intake, brine discharge and post-treatment respectively. Ultrafiltration is chosen as a general pre-treatment process and consumes approximately $0.3 \mathrm{kWh} / \mathrm{m}^{3}$ (Fane 2018).

Insufficient pre-treatment is most often the cause of RO system failure (Pearce 2008). Compared to conventional pre-treatment methods, membrane filtration processes such as ultrafiltration offer consistent and high-quality product water. Additionally, a smaller process footprint, less chemical dosage and fully automatic operation is possible when using UF (Xu et al. 2012). Suarez et al. (2015) offers one-year operational data for an UF-RO plant. According to their findings, the consistent high quality UF filtrate 
Table 2: System recovery $Y_{S}$, specific energy consumption (SEC), permeate salinity $C_{P}$ and number of UF modules $N_{U F}$ and RO modules $N_{R O}$ required for the UF-RO process at two varying inlet salinities $C_{I N}$

\begin{tabular}{ccccccc}
\hline$C_{I N}[\mathrm{~g} / \mathrm{L}]$ & $P_{R O}[$ bar $]$ & $Y_{S}[\%]$ & $S E C\left[\mathrm{kWh} / \mathrm{m}_{P}^{3}\right]$ & $C_{P}[\mathrm{~g} / L]$ & $N_{U F}$ & $N_{R O}$ \\
\hline 35 & 80 & 59.21 & 3.60 & 0.204 & 71 & 141 \\
70 & 80 & 23.27 & 5.14 & 0.640 & 180 & 359 \\
\hline
\end{tabular}

and reduced SDI in comparison to the previously installed multimedia filters improved reliability and operability of the desalination plant. However, biological growth within the system still remained an issue, as dissolved organics are not effectively reduced by UF. In Ma et al. (2007), the issue of RO membrane biofouling is addressed by an additional enhanced coagulation process installed prior to the UF process. This combined pre-treatment effectively reduced silica, iron and microbial contamination of the RO feed water to minimise biofilm formation on the $\mathrm{RO}$ membrane. As mentioned in Jamaly et al. (2014), low pressure membrane pre-filtration improves the reverse osmosis membrane lifespan by $20 \%$ to $30 \%$ and thus lowers the operational costs involved in frequent membrane replacement.

The recovery of the UF process is assumed to be

, an optimally reach only $95 \%$ due to frequent backwashing for fouling prevention (Jamaly et al. 2014). The number of UF and RO pressure vessels is based on a permeate production of $1000 \mathrm{~m}^{3} / \mathrm{h} . \quad N_{U F}$ is determined by assuming that 4

${ }_{645} \mathrm{X}$-Flow Aquaflex UF modules, each having an active membrane area of $60 \mathrm{~m}^{2}$, are placed in series in each pressure vessel (PentAir 2018). An average UF water flux of $100 \mathrm{LMH}$ is assumed (Xu et al. 2012).

As shown in figure 7 , it is assumed that a single pumping and energy recovery centre supplies all parallel RO trains. This principle is also chosen for the OARO process, as larger high efficiency pumps can be utilised to increase the pumping efficiency up to $85 \%$ (Voutchkov 2018). Indeed, this is done at the Ashkelon seawater desalination plant in Israel, where 4 high-pressure pumps supply seawater to $16 \mathrm{RO}$ trains to produce $50 \times 10^{6} \mathrm{~m}^{3} /$ year (Sauvet-Goichon 2007).

\section{The OARO integrated flow processes}

Five different OARO incorporated processes are displayed in figure 8 and figure 9 . For clarity, the feed side (FS) and draw side (DS) of each OARO process are indicated in the figures. As mentioned in section 1, the objective is to achieve a final system water recov$72 \%$ and $44 \%$ for a seawater inlet salinity of $35 \mathrm{~g} / \mathrm{L}$ and $70 \mathrm{~g} / \mathrm{L}$, respectively. These recoveries are obtained for each OARO integrated flow process, with various feed pressures $P_{O A}$ and total number of OARO stages $T$. In this work, the maximum number of OARO

stages is limited to $3(T \leq 3)$. Labels $S_{1}$ to $S_{4}$, that are displayed in figure 8 and figure 9 , are used to indicate the position of each OARO stage in the process.
An iterative approach is chosen to determine the steady state operation of each OARO integrated flow process. Every iteration commences by modelling each OARO and RO process independently, with its respective feed/draw flowrates and salinities. The iteration is then terminated by passing updated information between the processes before continuing with the following iteration. Steady state operation is reached once all flow streams converge and the salt and water conservation error is below $0.1 \%$ of the inlet salt and water flowrate.

Each OARO integrated flow process contains a maximum of 3 stages, with each stage containing several pressure vessels in parallel, where the feed flowrate per vessel is given by $Q_{F}$. Moser et al. (2015) mention that the cost of the membrane module is negligible compared to the cost of the pressure vessel. Therefore, it is financially beneficial to fit the maximum number of membrane modules into each pressure vessel. In section 4, 7 modules per pressure vessel are assumed for the RO process, as this is typical for large scale $\mathrm{RO}$ operations. An equivalent number of modules per pressure vessel is assumed for each OARO stage.

FO spiral wound membrane modules generally have a lower active membrane area (between $9 \mathrm{~m}^{2}$ and $15 \mathrm{~m}^{2}$ (Kim, Blandin, Phuntsho, Verliefde, Le-Clech \& Shon 2017)) than their RO counterparts. However, it is assumed that OARO modules can be designed with an RO equivalent active membrane area. An OARO membrane module with a high packing density should be plausible; Straub et al. (2014) employed a tightly woven permeate spacer from a commercial RO membrane to achieve a burst pressure of 48.3 bar. OARO pressure vessels are assumed to be in a similar price range as that of their RO counterparts, as both processes are operated at higher pressures.

Figure 10 shows the hydraulic and osmotic pressure profiles for three subsequent stages $\left(S_{1}\right.$ to $\left.S_{3}\right)$ in a single OARO process. Each stage is operated at the same inlet feed and draw pressure by employing booster pumps between each stage. These pumps are also modelled at a mechanical efficiency of $80 \%$. As shown in the figure, $\pi_{F}$ and $\pi_{D}$ vary in each stage, and depend on the process recovery and salt diffusion. Furthermore, no fouling or scaling of membrane surfaces are taken into account when determining $J_{W}$ and $J_{S}$.

\section{$5.1 \quad \mathrm{OA}-1$}

Two variations of this process, which has been proposed by Bartholomew et al. (2017), have been modelled. OA-1-1 is depicted in figure $8 \mathrm{a}$ and contains a single OARO loop with up to 3 stages in series $(T \geq 1)$. 


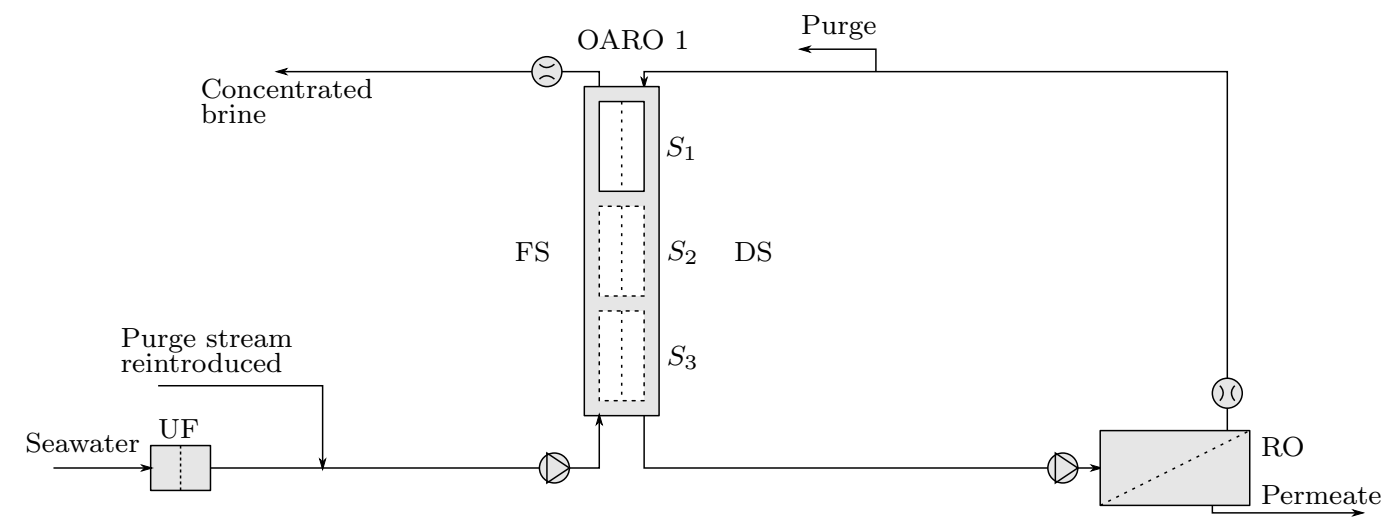

(a) OA-1-1

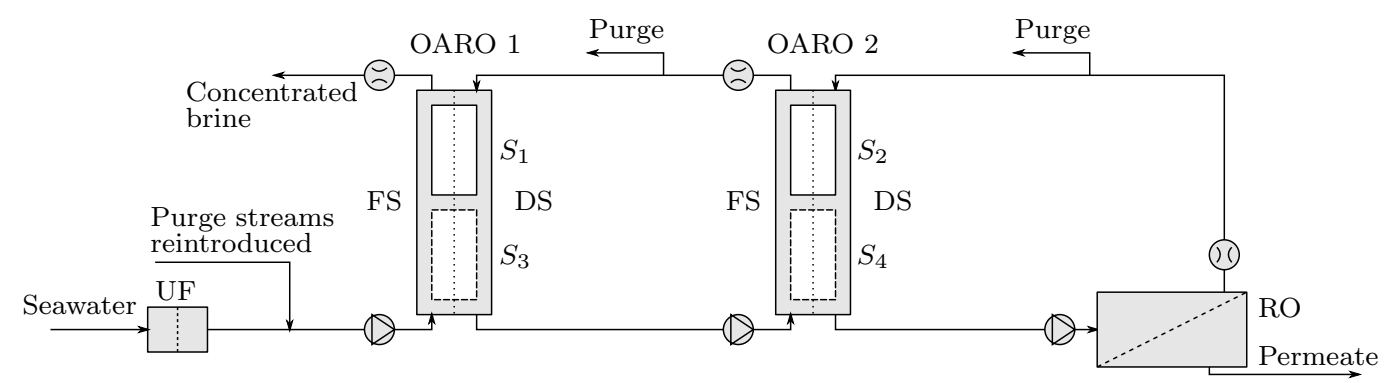

(b) OA-1-2. If this process is modelled with three stages $(T=3)$, then the third stage is either located at $S_{3}$ or $S_{4}$.

Figure 8: The first OARO integrated flow process that is being investigated

The RO process is not in direct contact with the seawater stream, but is instead supplied by the diluted draw stream of OARO1. The RO brine is then recirculated and reused in the OARO1 process as draw solution. On the other hand, OA-1-2 consists of one additional OARO loop with up to 3 stages split between OARO1 and OARO2, as depicted in figure 8b. OA-1-2 requires a minimum of two stages $(T \geq 2)$ situated at $S_{1}$ and $S_{2}$. If a third OARO stage is employed, then it is either situated at $S_{3}$ or at $S_{4}$. The diluted draw streams of OARO1 and OARO2 are further purified are reused as draw solutions in the previous membrane process, namely OARO1 and OARO2, respectively.

Due to the process layout, solute build-up or depletion in the individual loops occurs because of solute flux if no purge or replenishment streams are introduced (Bartholomew et al. 2017). The solute flux $J_{S}$ varies for each subsequent membrane process as process parameters, such as membrane selectivity, feed pressure, and stream salinities, may differ. As shown in figure 8 , solute concentration is controlled in each loop by incorporating purge streams. These purge streams are reintroduced on the feed side (FS) of OARO1, with the benefit of introducing water streams with a lower salinity than the concentrated brine stream being discharged.

\section{$5.2 \quad \mathrm{OA}-2$}

The second OARO integrated flow process is depicted in figure 9a, and has been adapted from Chen \& Yip (2018). The cascading OARO process is responsible for simultaneously concentrating the RO brine stream and diluting the $\mathrm{RO}$ feed stream, with up to 3 stages in series $(T \geq 1)$. Only a fraction of the RO feed stream is utilised as draw solution in OARO1, because $R R$ is set as 1 and the volumetric flowrate of the RO brine stream is lower than that of the OARO1 feed stream.

One set of high pressure pumps (HPPs) and energy recovery devices (ERDs) is utilised for each of the two high pressure membrane processes. Thus, $\mathrm{RO}$ can be operated at its optimal pressure while varying the feed pressure in OARO1 to achieve the set recoveries for each inlet salinity. In practice, two sets of HPPs and ERDs will be required because the OARO membrane modules have a lower burst pressure, as discussed in section 2 .

\section{$5.3 \quad \mathrm{OA}-3$}

Figure 9b depicts the third OARO integrated flow process, which has not been proposed previously. A secondary cascading OARO2 process is introduced. The advantage is that OARO2 dilutes the RO brine stream before it enters the first OARO1 process. Diluting the $\mathrm{RO}$ brine reduces the osmotic pressure difference be- 


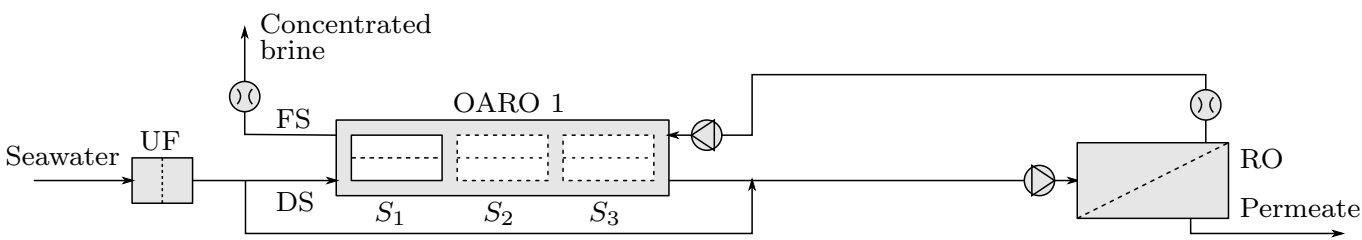

(a) OA-2

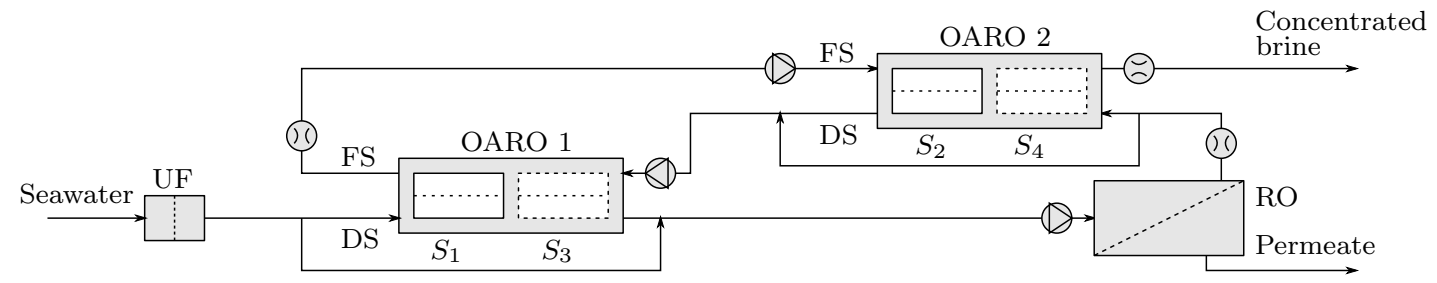

(b) OA-3

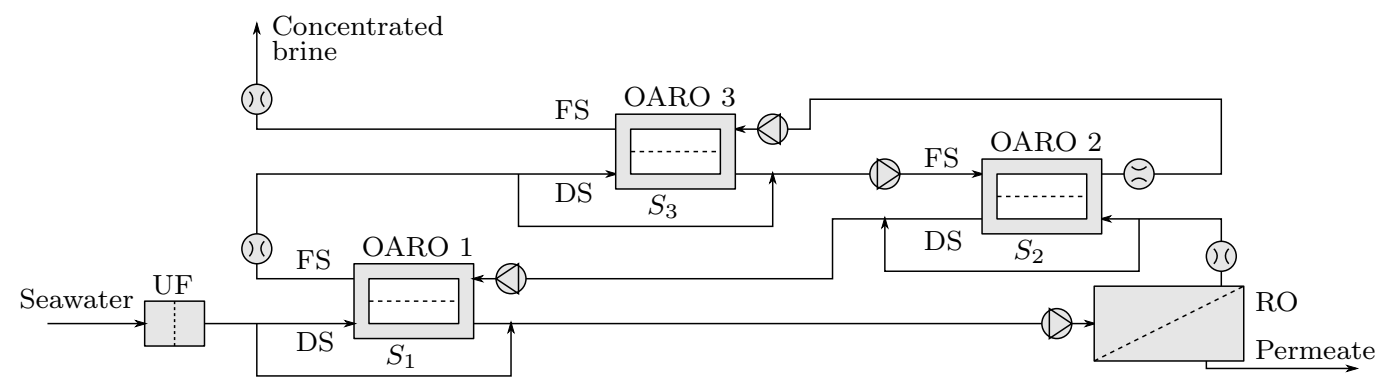

(c) OA-4

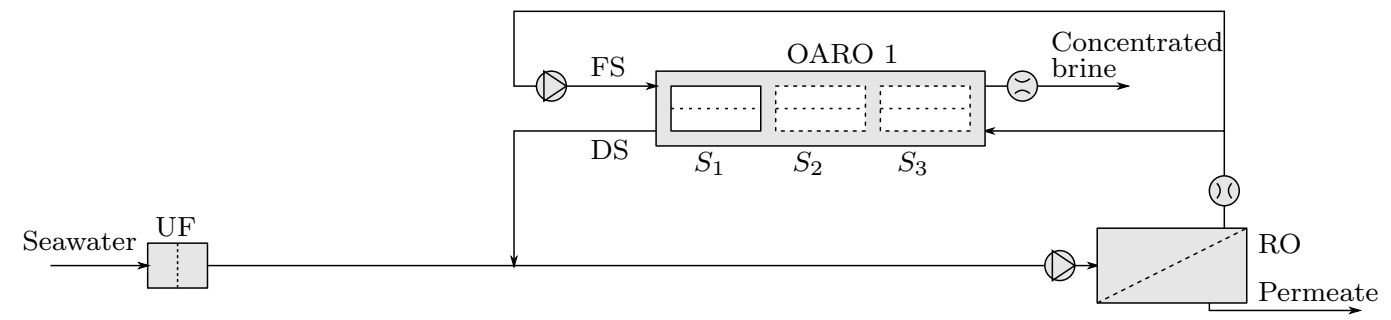

(d) OA-5

Figure 9: The other four OARO integrated flow processes that are being investigated

tween the two OARO1 inlet streams and allows for lower pressure operation. Furthermore, the irreversible Kim \& Hong 2018). The minimum number of stages is $2(T \geq 2)$, because at least one stage is required for each OARO process $\left(S_{1}\right.$ and $\left.S_{2}\right)$. If a third OARO stage is incorporated, then it is either situated at $S_{3}$ or

OA-3 is modelled with two additional sets of high pressure pumps and energy recovery devices, as shown in figure 9b. However, both OARO processes are placed in series and in principle a single set of high pressure pumps and energy recovery devices could be utilised for both OARO processes. Therefore, no increase in capital cost is expected when choosing OA-3 over OA-2.

\section{$5.4 \quad \mathrm{OA}-4$}

Similar to OA-3, the aim is to dilute each feed stream before it enters the following OARO module. This OARO integrated flow process incorporates a third cascading OARO3 process, and is depicted in figure 9c. In this case, it is not possible to operate all three OARO processes using a single set of HPPs and ERDs, as the brine stream is reused in OARO3 as draw solution and must be de-pressurised for the OARO3 process to function. OA-3 requires a minimum of 3 sets of high pressure pumps, but is modelled as depicted in figure 9c with 4. Furthermore, each OARO process requires at 


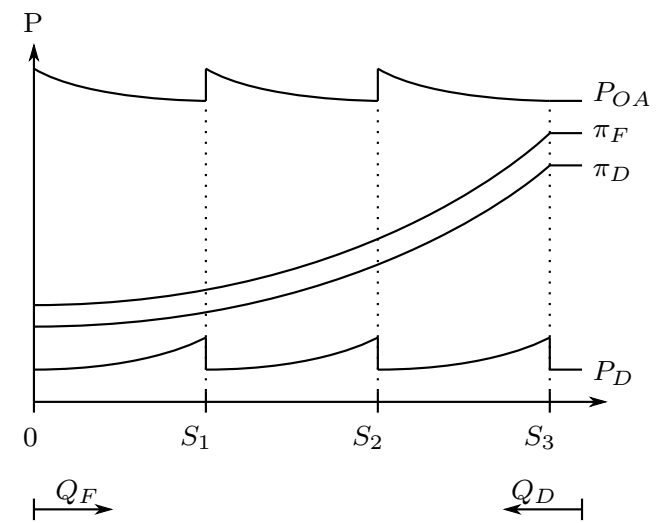

Figure 10: Pressure profile in an osmotically assisted reverse osmosis process with 3 stages in series.

least one stage, and therefore is only modelled with $T$ being 3 .

\section{$5.5 \quad \mathrm{OA}-5$}

In OA-5, an OARO process is integrated into a semibatch RO process, which has not been proposed before. As displayed in figure $9 \mathrm{~d}$, a fraction of the RO brine is used as draw solution to OARO1 and the other as feed solution to OARO1. The diluted brine stream is then recirculated and mixed with the original RO feed . The advantage of OA-5 compared to a standalone semi-batch RO process is that a lower concentrated brine is mixed with the initial feed. This reduces energy losses generated by mixing the two streams of different salinities (Werber et al. 2017). In terms of the OARO process itself, the advantage is that both streams enter the OARO1 process at the same concentration. Thus, the osmotic pressure difference is expected to be lower than for any of the previously presented OARO integrated flow processes. Furthermore, surised for OARO1 operation, which should minimise energy consumption.

\section{Simulation results and discus- sion}

830 In this section, all OARO integrated flow processes are evaluated for both recovery scenarios. Figure 11 shows the simulation results obtained for scenario $1\left(\mathrm{C}_{\mathrm{IN}}=35 \mathrm{~g} / \mathrm{L}\right.$ and $\left.\mathrm{Y}_{\mathrm{S}}=72 \%\right)$ and scenario 2 $\left(\mathrm{C}_{\mathrm{IN}}=70 \mathrm{~g} / \mathrm{L}\right.$ and $\left.\mathrm{Y}_{\mathrm{S}}=44 \%\right)$ on the left-hand and 35 right-hand columns, respectively. Although the final brine concentration is equivalent for both processes $(125 \mathrm{~g} / \mathrm{L})$, major differences in $P_{O A}$, specific energy consumption, required number of RO and OARO pressure vessels, and permeate salinity can be observed.

The shaded regions in figure 11 represent infeasible operating conditions. For $P_{O A}$, any transmembrane pressure exceeding the membrane burst pressure of 48.3 bar is not practical. The thermodynamic minimum energy of separation $E_{M i n}$ is determined by
(Chen \& Yip 2018):

$$
E_{M i n} \approx \frac{\pi_{F}}{Y_{S}} \ln \left(\frac{1}{1-Y_{S}}\right)
$$

where $Y_{S}$ is the system recovery. $E_{M i n}$ is indicated for both scenarios on the SEC plots by the shaded area. Furthermore, the maximum acceptable permeate salinity is assumed to be $0.5 \mathrm{~g} / \mathrm{L}$, and is also indicated by the shaded areas on the permeate salinity plots.

Scenario 1: $\mathrm{C}_{\mathrm{IN}}=35 \mathrm{~g} / \mathrm{L}$ and $\mathrm{Y}_{\mathrm{S}}=72 \%$

Of the five processes presented and according to the simulation results in figure 11 , only OA-5 with three OARO stages $(T=3)$ is capable of achieving the desired recovery while operating below the membrane burst pressure of 48.3 bar. Of the three cascading OARO integrated flow processes, OA-3 and OA-4 can be operated at significantly lower $P_{O A}$ than OA-2, as the transmembrane osmotic pressure in each OARO process is reduced. For example, in OA-3 the dilution of the $\mathrm{RO}$ brine stream by OARO2 reduces the osmotic pressure difference in OARO1. Furthermore, OARO2 utilises the RO brine stream as draw solution, which is more saline than the original seawater feed. Therefore, the osmotic pressure difference in OARO2 is also lower, as a stronger draw solution is utilised.

For the same total number of OARO stages, the permeate salinity, required number of pressure vessels and energy consumption are almost equivalent for all three processes. However, OA-3 is the most feasible cascading OARO integrated flow process, as it achieves the same recovery at the lowest $P_{O A}$. Furthermore, in principle OA-3 requires only a single set of high pressure pumps to supply both OARO processes, which is not possible for OA-4.

In OA-1, the OARO process assumes the role of an additional pre-treatment process. All water has to pass through OARO1 (and OARO2 for OA-1-2) before reaching the RO process. While this can be beneficial for high salinity and/or high fouling/scaling streams, it comes at a significantly higher operational and capital cost. Each additional loop requires its own set of HPPs and ERDs and the process footprint increases significantly, as more piping is required. Comparing OA1-1 with the other OARO integrated flow processes, at least $28 \%$ more energy is consumed and $37 \%$ more pressure vessels are required when using a total of three OARO stages $(T=3)$.

The results in figure 11 indicate that adding a secondary OARO loop in OA-1 further increases the operational and capital expenditures and is not advised, as OA-1-1 is capable of operating at lower $P_{O A}$ and producing a permeate of sufficient quality. Furthermore, each additional loop requires its own set of HPPs and ERDs and the process footprint increases significantly as more piping is required.

OA-5 requires three stages and a minimum feed pressure of 43.5 bar to operate scenario 1. Further advantages of OA-5 include low operational and capital costs, as it is the most energy efficient process requiring the 

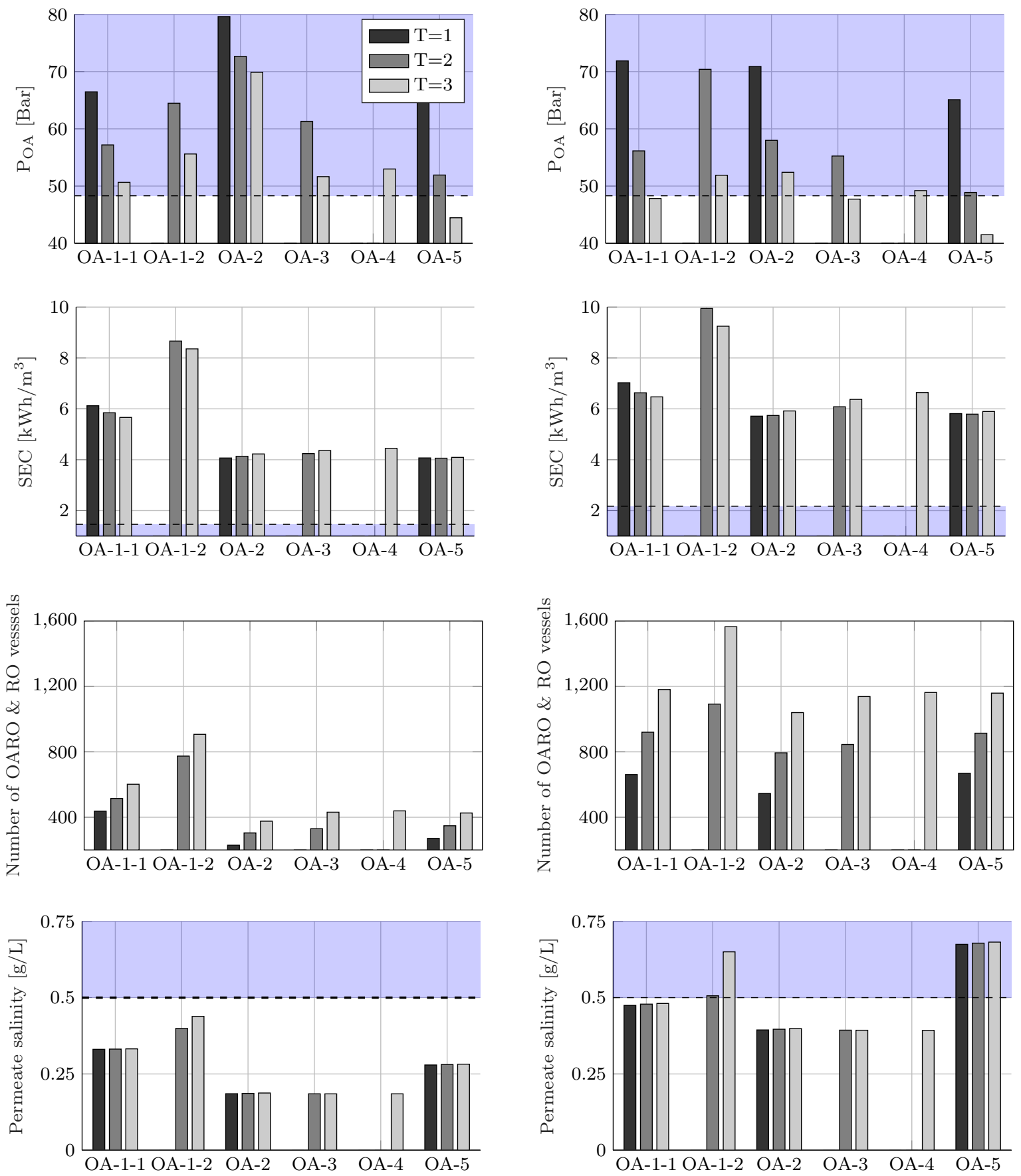

Figure 11: Simulation results for the OARO integrated flow processes for scenario 1 $\left(\mathrm{C}_{\mathrm{IN}}=35 \mathrm{~g} / \mathrm{L}\right.$ and $\left.\mathrm{Y}_{\mathrm{S}}=72 \%\right)$ in the left column, and scenario $2\left(\mathrm{C}_{\mathrm{IN}}=70 \mathrm{~g} / \mathrm{L}\right.$ and $\left.\mathrm{Y}_{\mathrm{S}}=44 \%\right)$ in the right column. The shaded regions indicate infeasible operating regions. In the SEC plots, the thermodynamic minimum energy for both scenarios is indicated by the dashed lines above the shaded regions.

least amount of pressure vessels (when excluding OA2 , as it is infeasible). The only disadvantage of OA-5 is the reduced permeate quality, which is, however, still acceptable according to the drinking water standards
To conclude, OA-5 shows the best performance and is technically feasible for recovering $72 \%$ freshwater from a feed stream with an inlet concentration of $35 \mathrm{~g} / \mathrm{L}$.
Scenario 2: $\mathrm{C}_{\mathrm{IN}}=70 \mathrm{~g} / \mathrm{L}$ and $\mathrm{Y}_{\mathrm{S}}=44 \%$

Recovering $44 \%$ freshwater from a $70 \mathrm{~g} / \mathrm{L}$ saline brine is more complicated than for the first scenario, although both concentrated brine streams reach the same outlet salinity of $125 \mathrm{~g} / \mathrm{L}$. This is evidenced by the generally larger number of required pressure vessels, higher energy consumption and lower permeate quality for Scenario 2 than for Scenario 1.

Due to the lower process recovery of $44 \%$, higher flowrates are observed in the entire OARO integrated flow process at fixed permeate volume. Thus, more pressure vessels are required to produce the same 
amount of permeate for higher salinity brine streams. Dewatering more saline brines also comes at the cost of a lower permeate quality. While it is still at acceptable levels for most of the OARO integrated processes, OA-1-2 and OA-5 would require a secondary RO pass to reduce the permeate salinity to acceptable limits. Furthermore, dewatering more saline brines is inherently more energy intensive. This is evidenced by an increase in the theoretical minimum energy of separation from $1.46 \mathrm{kWh} / \mathrm{m}^{3}$ to $2.17 \mathrm{kWh} / \mathrm{m}^{3}$ for Scenario 1 and 2 , respectively.

However, one advantage in Scenario 2 is that higher feed concentrations lower the required OARO feed ure, as the transmembrane osmotic pressure difference is reduced. For example, in OA-2 the RO brine salinity is relatively constant for both scenarios, but the higher feed salinity results in a stronger draw solution in the OARO process. Therefore, three of the 940 five proposed OARO integrated flow processes (OA-11 , OA-3 and OA-5) are capable of recovering $44 \%$ of freshwater from a $70 \mathrm{~g} / \mathrm{L}$ saline feed, while operating below the OARO membrane burst pressure.

Similar to the first scenario, OA-2 is the least feasible process, as its minimum operating pressure is approximately 4 bar greater than the OARO membrane burst pressure. The best performing OARO integrated flow process at the higher feed concentration is OA-3, as it can be operated at the lowest $P_{O A}$ while achieving an acceptable permeate quality (unlike OA-5).

The increase in energy consumption between Scenario 1 and Scenario 2 is more significant for OA-2 to OA-5 than for OA-1. This is explainable by the direct relationship between the inlet and $\mathrm{RO}$ feed salinity for 1 is more constant between Scenarios 1 and 2. At even higher inlet feed salinities, the only viable process will be OA-1 with one or more loops, as the RO feed salinity is better regulated by separating the $\mathrm{RO}$ process from the feed stream. For scenario 1, the difference in the required number of pressure vessels between OA-1 and the other OARO integrated flow process was more pronounced. This is not the case for scenario 2 , in which OA-1 becomes more competitive.

\section{OARO vs. multi-stage RO (MSRO)}

From the previous discussion, it becomes evident that OA-5 and OA-3 are the optimal OARO integrated flow processes for Scenario 1 and 2, respectively. However, the question still remains: how do these OARO integrated flow processes compare to other high recovery processes?

Of the available high recovery processes, thermal processes are the most widely used, but are inherently inefficient (Davenport et al. 2018). MVC consumes between $20 \mathrm{kWh} / \mathrm{m}^{3}$ and $39 \mathrm{kWh} / \mathrm{m}^{3}$ of electrical energy (Tong \& Elimelech 2016), whereas OA-5 consumes at least $79 \%$ less energy when operating at the burst pressure. However, mechanical vapour compression can operate at salinities up to $250 \mathrm{~g} / \mathrm{L}$, recover up to $98 \%$ of
Elimelech 2016). At the current stage, this is not possible using OARO integrated flow processes.

FO and PAFO are membrane processes employing a draw solution, which is similar to OARO, but are plagued by more severe ICP, as mentioned in section 2.1. Besides, the recovery of the osmotic draw solution is more energy intensive for $\mathrm{FO} / \mathrm{PAFO}$, due to the comparatively higher draw solute concentration required to achieve the same system recovery $Y_{S}$. OARO can potentially be operated at similar water fluxes as SWRO and no expensive, purpose-made draw solute is lost by reverse solute flux, which further makes OARO more economically viable than $\mathrm{FO} / \mathrm{PAFO}$.

Only multi-stage RO (MSRO) is directly comparable to OARO, as it is a pressure-driven membrane process and currently the most energy efficient continuous process. Therefore, MSRO is modelled for Scenario 1 and 2 , with the results presented in table 3 . All presented processes in table 3 have 4 stages, including the terminal RO stage. All MSRO stages are operated at the same recovery by increasing the hydraulic pressure in each subsequent stage. This requires the use of interstage booster pumps, but is beneficial for energy cost reduction and balancing the water flux in each stage. In practice, this operation reduces the fouling potential in the initial membrane modules (Werber et al. 2017). For the MSRO process, the feed flowrate in each RO stage is kept constant at $12 \mathrm{~m}^{3} / \mathrm{h}$. As mentioned in section 4, large scale RO plants are generally operated at similar feed flowrates. A reduction in feed flowrate causes the permeate quality to worsen, increases the required number of pressure vessels and the RO operating pressure is not significantly reduced. In table 3 , $P_{R O}$ represents the maximum required operating pressure in the final stage of the MSRO process.

The MSRO process is more energy efficient, because dilution and mixing of the saline streams in the OARO process increases entropy and thus diminishes the net energy efficiency (Chen \& Yip 2018). Additionally, less pressure vessels are required in the MSRO process, as permeate is directly produced and no additional dilution steps are required. The latter increases the volume flowrates in the OARO integrated processes (i.e. more pressure vessels are required).

However, the last MSRO stage has to be operated at pressures above the typical maximum RO operating pressure of 80 bar. As mentioned in Davenport et al. (2018), DOW offers spiral wound RO membrane modules that can be operated at high pressures of up to 120 bar, due to special membrane and module designs (The Dow Chemical Co.: Midland 2018). These, however, have a significantly lower membrane area of $6.2 \mathrm{~m}^{2}$ than the standard RO modules assumed here with an active membrane area of $37 \mathrm{~m}^{2}$. Thus, higher operating pressures, lower flowrates or more MSRO stages would be required to achieve the desired recoveries using MSRO.

Indeed, adding more MSRO stages or reducing the flowrate would further worsen the permeate quality and increase the capital expenditure. A secondary RO 1040 pass is required for MSRO in scenario 2 to achieve the 
Table 3: Comparison of OARO vs MSRO for the two scenarios. For this comparison, the OARO integrated flow processes are modelled with a total of three OARO stages and the terminal RO stage. Similarly, MSRO has an equivalent number of stages (4), including the terminal RO stage.

\begin{tabular}{ccccccc}
\hline Scenario & Process & $P_{O A} / P_{R O}[b a r]$ & $S E C\left[k W h / m_{P}^{3}\right]$ & $C_{P}[g / L]$ & $N_{O A}$ & $N_{R O}$ \\
\hline 1 & OA-5 & 45.5 & 4.09 & 0.282 & 247 & 179 \\
1 & MSRO & 103.5 & 3.32 & 0.429 & 0 & 308 \\
2 & OA-3 & 48.7 & 6.37 & 0.393 & 901 & 237 \\
2 & MSRO & 102.5 & 5.16 & 1.220 & 0 & 619 \\
\hline
\end{tabular}

required permeate quality. In contrast, OA-3 achieves an acceptable permeate quality and no secondary $\mathrm{RO}$ pass is required.

To conclude, the high MSRO operating pressures required make the process impractical for high recovery processes. On the other hand, OARO integrated flow processes operate at viable pressures and offer a superior permeate quality compared to their MSRO counterparts. The difference in capital cost between the two processes is negligible, as MSRO either requires more stages to achieve the same recovery as OARO or needs a secondary RO pass to ensure an adequate permeate quality.

\section{OARO prospects and future development}

The main objective of an OARO integrated flow process is to achieve higher process recoveries to minimise the brine volume. Increasing the number of stages would also achieve this, but would raise the capital cost unnecessarily. Adding more stages becomes less effective, as more stages result in the process operating closer to the equilibrium state and at a lessened driving force. Another option would be to reduce the process flowrate, as discussed in section 3.2. This would, however also result in higher capital expenditures and increase the membrane fouling/scaling propensity. Optimally, OARO membrane modules should be developed that have a high packing density and are operable at higher feed pressures.

Table 4 shows the potential improvements of OA- 5 if more permeable membranes (NF90) with thin support layers can be developed, or if the burst pressure can be raised to 70 bar. The major advantage of higher operating pressures is the reduction in capital cost while ing the system recovery. The more permeable NF90 membrane allows for even higher recoveries, but at the expense of a higher capital cost incurred by more OARO and RO pressure vessels. As shown in table 1, the NF90 membrane is more permeable than the TFC- brane permeability and lower selectivity increase the OARO draw solution volume and its salinity, respectively. This increases the overall volume flowrates in the OARO integrated processes and thus more pressure vessels are required.

Davenport et al. (2018) mentions that the development of new permeate spacers is important for the further development of high pressure reverse osmosis. This development would also benefit the OARO process, as both permeate spacers should have the same characteristics. Both spacers should minimise membrane deformation into spacer voids, while not increasing the frictional pressure losses.

\section{Conclusions}

In this article, five OARO integrated flow processes are presented. These are compared according to their technical and economic feasibility, at $72 \%$ and $44 \%$ freshwater recoveries from water sources with respective salinities of $35 \mathrm{~g} / \mathrm{L}$ and $70 \mathrm{~g} / \mathrm{L}$. Prior to modelling the entire process, the stand-alone OARO process was investigated and the optimal OARO process parameters were determined. The influence of each OARO parameter can be summarised as follows:

Membrane properties: Higher recoveries at lower energy consumption are achieved for more permeable membranes, but the achieved draw dilution is less significant.

Feed flowrate: A moderate flowrate balances the capital cost and increased fouling/scaling propensity against higher energy costs and lower recoveries.

Flowrate ratio: Lower $R R$ values are more practical to prevent excessive pressure losses in the draw channel.

Feed pressure: An increase in $P_{O A}$ is beneficial as the energy consumption is relatively constant

Table 4: Prospective improvements in OARO membrane and module development for OA-5 with $S_{T}=3$ and $C_{I N}=35 \mathrm{~g} / \mathrm{L}$ : for each membrane, the effect of increasing the burst pressure to 70 bar is shown.

\begin{tabular}{cccccccc}
\hline Membrane & $P_{O A}[$ bar $]$ & $Y_{S}[\%]$ & $S E C\left[k W h / m_{P}^{3}\right]$ & $C_{P}[g / L]$ & $N_{U F}$ & $N_{O A}$ & $N_{R O}$ \\
\hline TFC-FO & 48.3 & 72.2 & 4.00 & 0.235 & 58 & 249 & 156 \\
TFC-FO & 70.0 & 77.4 & 4.25 & 0.226 & 54 & 210 & 152 \\
NF90 & 48.3 & 73.5 & 4.13 & 0.247 & 57 & 254 & 162 \\
NF90 & 70.0 & 78.8 & 4.47 & 0.242 & 53 & 214 & 159 \\
\hline
\end{tabular}


while a higher draw dilution and recovery is achieved. However, $P_{O A}$ is limited by the membrane burst pressure.

Of the five OARO integrated flow processes, OA5 shows the best performance at lower feed concentrations. It is the only technically feasible process to achieve the desired process recovery with a maximum of three OARO stages. OA-5 also has the second lowest energy consumption and capital expenditure after OA2 , which is however the least feasible OARO integrated flow process. Furthermore, the permeate salinity for OA-5 is of acceptable quality according to the WHO drinking water guidelines. At the higher inlet salinity, sonable permeate quality while achieving the desired recovery at feasible OARO feed pressures.

OARO integrated processes are economically viable alternatives to current brine dewatering techniques, as hey offer the possibility to achieve high system recoveries at comparatively lower energy costs and operating pressures. Pressure driven membrane processes have proven to be significantly more energy efficient than their thermal counterparts. Furthermore, the lower specific energy consumption of OARO in comparison to other chemically driven membrane processes, such as $\mathrm{FO} / \mathrm{PAFO}$, make it an economically viable process addition for brine volume minimisation. In comparison to MSRO, OARO is technically feasible to achieve the 1145 desired brine concentration. High pressure RO, MSRO, FO/PAFO and OARO are not mutually exclusive processes and can be combined to eventually achieve brine concentrations of up to $250 \mathrm{~g} / \mathrm{L}$ in a more cost efficient and sustainable manner to compete with or replace

\section{Acknowledgements}

The authors would like to thank the University of Bahrain (in the Kingdom of Bahrain) for supporting and funding this research work.

\section{References}

Alsvik, I. L. \& Hägg, M.-B. (2013), 'Pressure retarded osmosis and forward osmosis membranes: Materials and methods', Polymers 5(1), 303-327.

Altaee, A. (2012), 'Computational model for estimating reverse osmosis system design and performance: Part-one binary feed solution', Desalination 291, 101 - 105.

Bartholomew, T. V., Mey, L., Arena, J. T., Siefert, N. S. \& Mauter, M. S. (2017), 'Osmotically assisted reverse osmosis for high salinity brine treatment', Desalination 421, 3-11. The Latest Advances and Opportunities in Forward Osmosis.

Blandin, G., Myat, D. T., Verliefde, A. R. \& Le-Clech, P. (2017), 'Pressure assisted osmosis using nanofiltration membranes (pao-nf): Towards higher efficiency osmotic processes', Journal of Membrane Science 533, 250 - 260.

Chen, X. \& Yip, N. Y. (2018), 'Unlocking high-salinity desalination with cascading osmotically mediated reverse osmosis: Energy and operating pressure analysis', Environmental Science \& Technology 52(4), 2242-2250. PMID: 29357240.

\begin{tabular}{ll}
\hline Abbreviations \\
AL-DS & Active layer - draw side \\
AL-FS & Active layer - feed side \\
BWRO & Brackish water reverse osmosis \\
CTA & Cellulose acetate \\
DS & Draw side \\
ECP & External concentration polarisation \\
ERD & Energy recovery device \\
FO & Forward osmosis \\
FS & Feed side \\
HPP & High pressure pump \\
ICP & Internal concentration polarisation \\
MSRO & Multi-stage reverse osmosis \\
MVC & Mechanical vapour compression \\
OARO & Osmotically assisted reverse osmosis \\
PAFO & Pressure assisted FO \\
PRO & Pressure retarded osmosis \\
ROSA & RO system analysis software \\
SEC & Specific energy consumption \\
SDI & Silt density index \\
SWRO & Seawater reverse osmosis \\
TDS & Total dissolved solids \\
TFC & Thin-film composite \\
TMP & Transmembrane pressure \\
UF & Ultrafiltration \\
WHO & World Health Organisation \\
&
\end{tabular}

\section{Nomenclature}

A Water permeability coefficient, $L \cdot m^{-2} \cdot s^{-1} \cdot b a r^{-1}$

$B \quad$ Salt permeability coefficient, $L \cdot m^{-2} \cdot h^{-1}$

$C_{D} \quad$ Draw concentration, $g \cdot L^{-1}$

$C_{F} \quad$ Feed concentration, $g \cdot L^{-1}$

$C_{P} \quad$ Permeate concentration, $g \cdot L^{-1}$

$C_{I N} \quad$ Inlet concentration, $g \cdot L^{-1}$

$C P \quad$ Concentration polarisation factor

$D \quad$ Diffusivity coefficient, $\mathrm{m}^{2} \cdot \mathrm{s}^{-1}$

$E_{M i n} \quad$ Minimum energy of separation

$J_{S} \quad$ Salt flux, $g \cdot m^{-2} \cdot h^{-1}$

$J_{W} \quad$ Water flux, $L \cdot m^{-2} \cdot h^{-1}$

$K \quad$ Mass transfer resistance, $m^{2} \cdot h \cdot L^{-1}$

$k_{D} \quad$ Mass transfer coefficient in draw stream, $L \cdot m^{-2} \cdot h^{-1}$

$k_{F} \quad$ Mass transfer coefficient in feed stream, $L \cdot m^{-2} \cdot h^{-1}$

$k_{M} \quad$ Mass transfer coefficient in the membrane, $L \cdot m^{-2} \cdot h^{-1}$

$N_{O A} \quad$ Number of OARO pressure vessels

$N_{R O} \quad$ Number of RO pressure vessels

$N_{U F} \quad$ Number of UF pressure vessels

$n_{O A} \quad$ Number of OARO modules in series

$P_{H i g h} \quad$ High feed pressure, bar

$P_{L} \quad$ Pressure loss, bar

$P_{\text {Low }} \quad$ Low feed pressure, bar

$P_{O A} \quad$ OARO feed pressure, bar

$P_{R O} \quad$ Maximum RO feed pressure, bar

$Q_{D} \quad$ Draw flowrate, $m^{3} \cdot s^{-1}$

$Q_{F} \quad$ Feed flowrate, $m^{3} \cdot s^{-1}$

$Q_{P} \quad$ Permeate flowrate, $m^{3} \cdot s^{-1}$

$R R \quad$ Ratio between draw and feed flowrate 


\begin{tabular}{|ll|}
\hline Nomenclature \\
$S$ & Structural parameter, $m$ \\
$S_{1}$ to $S_{4}$ & Label to indicate OARO stage position \\
$T$ & Total number of OARO stages \\
$Y_{S}$ & System recovery, \% \\
$\Delta P$ & Transmembrane pressure difference, bar \\
$\Delta \pi$ & Osmotic pressure difference, bar \\
$\pi_{D}$ & Osmotic pressure of draw solution, bar \\
$\pi_{F}$ & Osmotic pressure of feed solution, bar \\
$\pi_{H i g h}$ & High osmotic pressure, bar \\
$\pi_{\text {Low }}$ & Low osmotic pressure, bar \\
\end{tabular}

Davenport, D. M., Deshmukh, A., Werber, J. R. \& Elimelech, M. (2018), 'High-pressure reverse osmosis for energy-efficient hypersaline brine desalination: Current status, design considerations, and research needs', Environmental Science $\&$ Technology Letters 5, 467-475.

DOW Water Solutions (2017a), Filmtec Membranes: Product Information Catalog.

DOW Water Solutions (2017b), FILMTEC Reverse Osmosis Membranes: Technical Manual.

Duan, J., Litwiller, E. \& Pinnau, I. (2014), 'Solution-diffusion with defects model for pressure-assisted forward osmosis', Journal of Membrane Science 470, 323 - 333.

Elimelech, M. \& Phillip, W. A. (2011), 'The future of seawater desalination: Energy, technology, and the environment', Science 333(6043), 712-717.

URL: http://science.sciencemag.org/content/333/6043/712

Fane, A. T. (2018), 'A grand challenge for membrane desalination: More water, less carbon', Desalination 426, 155 - 163.

Henthorne, L. \& Boysen, B. (2015), 'State-of-the-art of reverse osmosis desalination pretreatment', Desalination 356, 129 139. State-of-the-Art Reviews in Desalination.

Hickenbottom, K. L., Vanneste, J., Elimelech, M. \& Cath, T. Y. (2016), 'Assessing the current state of commercially available membranes and spacers for energy production with pressure retarded osmosis', Desalination 389, 108 - 118. Pressure Retarded Osmosis.

Jamaly, S., Darwish, N., Ahmed, I. \& Hasan, S. (2014), 'A short review on reverse osmosis pretreatment technologies', Desalination 354, $30-38$.

Jeon, J., Jung, J., Lee, S., Choi, J. Y. \& Kim, S. (2018), 'A simple modeling approach for a forward osmosis system with a spiral wound module', Desalination 433, 120 - 131.

Johnson, D. J., Suwaileh, W. A., Mohammed, A. W. \& Hilal, N. (2018), 'Osmotic's potential: An overview of draw solutes for forward osmosis', Desalination 434, 100 - 120. Reviews on Research and Development in Desalination.

Kim, B., Gwak, G. \& Hong, S. (2017), 'Analysis of enhancing water flux and reducing reverse solute flux in pressure assisted forward osmosis process', Desalination 421, $61-71$. The Latest Advances and Opportunities in Forward Osmosis.

Kim, J., Blandin, G., Phuntsho, S., Verliefde, A., Le-Clech, P. \& Shon, H. (2017), 'Practical considerations for operability of an 8" spiral wound forward osmosis module: Hydrodynamics, fouling behaviour and cleaning strategy', Desalination 404, $249-258$.

Kim, J., Kim, D. I. \& Hong, S. (2018), 'Analysis of an osmotically-enhanced dewatering process for the treatment of highly saline (waste)waters', Journal of Membrane Science 548, $685-693$.
Kim, J., Kim, J., Kim, J. \& Hong, S. (2018), 'Osmotically enhanced dewatering-reverse osmosis (oed-ro) hybrid system: Implications for shale gas produced water treatment', Journal 1225 of Membrane Science 554, 282 - 290.

Ma, W., Zhao, Y. \& Wang, L. (2007), 'The pretreatment with enhanced coagulation and a uf membrane for seawater desalination with reverse osmosis', Desalination 203(1), 256 - 259. EuroMed 2006.

Madsen, H. T., Nissen, S. S., Muff, J. \& Søgaard, E. G. (2017) 'Pressure retarded osmosis from hypersaline solutions: Investigating commercial fo membranes at high pressures', Desalination 420, $183-190$.

Morillo, J., Usero, J., Rosado, D., Bakouri, H. E., Riaza, A. ${ }_{1235}$ \& Bernaola, F.-J. (2014), 'Comparative study of brine management technologies for desalination plants', Desalination 336, $32-49$.

Moser, M., Trieb, F., Fichter, T., Kern, J. \& Hess, D. (2015), 'A flexible techno-economic model for the assessment of desalination plants driven by renewable energies', Desalination and Water Treatment 55(11), 3091-3105.

Oh, Y., Lee, S., Elimelech, M., Lee, S. \& Hong, S. (2014), 'Effect of hydraulic pressure and membrane orientation on water flux and reverse solute flux in pressure assisted osmosis', Journal of Membrane Science 465, 159 - 166.

Pearce, G. (2008), 'Uf/mf pre-treatment to ro in seawater and wastewater reuse applications: a comparison of energy costs', Desalination 222(1), 66 - 73. European Desalination Society and Center for Research and Technology Hellas (CERTH), 25 April 2007, Halkidiki, Greece.

PentAir (2018), 'X-flow: Aquaflex', Online.

URL: https://xflow.pentair.com/en/products/aquaflex

Pohl, R., Kaltschmitt, M. \& Holländer, R. (2009), 'Investigation of different operational strategies for the variable operation of a simple reverse osmosis unit', Desalination 249(3), 1280 1287 .

Sauvet-Goichon, B. (2007), 'Ashkelon desalination plant: A successful challenge', Desalination 203(1), 75 - 81. EuroMed 2006.

Semiat, R. (2000), 'Present and future', Water International 25(1), 54-65.

Shaffer, D. L., Werber, J. R., Jaramillo, H., Lin, S. \& Elimelech, M. (2015), 'Forward osmosis: Where are we now?', Desalination 356, 271 - 284. State-of-the-Art Reviews in Desalination.

Straub, A. P., Yip, N. Y. \& Elimelech, M. (2014), 'Raising the bar: Increased hydraulic pressure allows unprecedented high power densities in pressure-retarded osmosis', Environmental Science \&5 Technology Letters 1(1), 55-59.

Suarez, J., Salgado, B., Casanas, A., Gonzalez, J. C. \& Pordomingo, J. (2015), 'One-year operational experience with ultrafiltration as pretreatment of seawater reverse osmosis desalination system (maspalomas-i plant)', Desalination and Water Treatment 55(10), 2813-2821.

The Dow Chemical Co.: Midland, M. (2018), DOW Specialty Membrane XUS180804 and XUS180802 Reverse Osmosis Elements Product Data Sheet.

Tong, T. \& Elimelech, M. (2016), 'The global rise of zero liquid discharge for wastewater management: Drivers, technologies, and future directions', Environmental Science $\&$ Technology 50(13), 6846-6855. PMID: 27275867.

Tsai, J.-H., Macedonio, F., Drioli, E., Giorno, L., Chou, C.Y., Hu, F.-C., Li, C.-L., Chuang, C.-J. \& Tung, K.-L. (2017), 'Membrane-based zero liquid discharge: Myth or reality?', Journal of the Taiwan Institute of Chemical Engineers 80, $192-202$. 
Voutchkov, N. (2018), 'Energy use for membrane seawater desalination: Current status and trends', Desalination 431.

URL: https://doi.org/10.1016/j.desal.2017.10.033

Wang, P., ed. (2016), Smart Materials for Advanced Environmental Applications, Smart Materials Series, The Royal Society of Chemistry.

Werber, J. R., Deshmukh, A. \& Elimelech, M. (2016), 'The critical need for increased selectivity, not increased water permeability, for desalination membranes', Environmental Science \&6 Technology Letters 3(4), 112-120.

Werber, J. R., Deshmukh, A. \& Elimelech, M. (2017), 'Can batch or semi-batch processes save energy in reverse-osmosis desalination?', Desalination 402, 109 - 122.

1300 Xiao, D., Li, W., Chou, S., Wang, R. \& Tang, C. Y. (2012) 'A modeling investigation on optimizing the design of forward osmosis hollow fiber modules', Journal of Membrane Science 392-393, $76-87$.

Xu, J., Ruan, L. G., Wang, X., Jiang, Y. Y., Gao, L. X. \& Gao, J. C. (2012), 'Ultrafiltration as pretreatment of seawater desalination: Critical flux, rejection and resistance analysis', Separation and Purification Technology 85, 45 - 53.

Yip, N. Y. \& Elimelech, M. (2011), 'Performance limiting effects in power generation from salinity gradients by pressure retarded osmosis', Environmental Science \& Technology 45(23), 10273-10282. PMID: 22022858.

Zhou, D., Zhu, L., Fu, Y., Zhu, M. \& Xue, L. (2015), 'Development of lower cost seawater desalination processes using nanofiltration technologies — a review', Desalination 376, 109 $-116$. 